\title{
Retraction Note: Image classification-based groundwater pollution prediction and regional economic collaborative innovation
}

\author{
Yan Zhang ${ }^{1}$
}

Published online: 29 November 2021

C) Saudi Society for Geosciences 2021

Retraction Note: Arabian Journal of Geosciences (2021) 14: 1710

https://doi.org/10.1007/s12517-021-07807-8

The Editor-in-Chief and the Publisher have retracted this article because the content of this article is nonsensical. The peer review process was not carried out in accordance with the Publisher's peer review policy. The author has not responded to correspondence regarding this retraction.

The original article can be found online at https://doi.org/10.1007/ s12517-021-07807-8.

Yan Zhang

yanzhang821205@163.com

1 College of Urban and Rural Planning and Architectural

Engineering, Shangluo University, Shangluo 726000,

Shaanxi, China 